\title{
TỒN TẠI ĐộNG MẠCH NGỒI ĐƯợC PHÁT HIỆN QUA MỘT TRƯờNG HợP TẮC MẠCH CHI CẤP TÍNH
}

\author{
Nguyê̂n Ngọc Trung*, Vũ Đức Thắng*, Trần Đức Hùng*, Phạm Vũ Thu Hà*, Lê Bá Hạnh*, \\ Khuất Duy Hòa*, Hoàng Thế Anh*, Nguyễn Thế Kiên*
}

\section{TÓM TÁT}

Mục đích: Tồn tại động mạch (ĐM) ngồi là tình trạng hiếm gặp, chỉ chiếm $0,025 \%$ - 0,05\%. Bệnh nhân thường nhập viện vì các biến chứng như tắc mạch, thiếu máu mạn tính hoặc phình ĐM ngồi.

Phương pháp: Chúng tôi xin chia sẻ kinh nghiệm chẩn đoán và điều trị một trường hợp, bệnh nhân nữ, 70 tuổi, vào viện sau 3 ngày bị tắc cấp tính do huyết khối từ động mạch chậu gốc trái, được phẫu thuật lấy huyết khối. Chụp cắt lớp vi tính mạch máu (CTA) và siêu âm sau mổ phát hiện tồn tại ĐM ngồi hai bên và huyết khối gây tắc ĐM ngồi bên trái.

Kết quả: Điều trị nội khoa đạt kết quả khả quan sau 3 tháng phẫu thuật. Bệnh nhân hết tình trạng đau cách hồi. Siêu âm cho kết quả lưu thông động mạch chày trước, chày sau bình thường.

Kết luận: Tồn tại động mạch ngồi là tình trạng rất hiếm gặp. Chẩn đoán chủ yếu dựa vào CTA và siêu âm. Lựa chọn phương pháp điều trị phụ thuộc vào đặc điểm bất thường giải phẫu.

Tù khóa: động mạch ngồi, huyết khối, tắc mach.

\section{DIAGNOSIS A PERSISTENT SCIATIC ARTERY IN PATIENT WITH ACUTE LOWER LIMB THROMBOSIS}

\section{ABSTRACT:}

Objective: Persistent sciatic artery (PSA) is a rare abnormal vascular condition, accounting for only $0.025 \%-0.05 \%$. Patients are often hospitalized because of complications such as embolism, chronic anemia or aneurysms sciatic artery.

Method: We present a case of 70-year-old female patient admitted to the hospital after 3 days of acute obstruction due to a thrombus from the left common iliac artery. Computed tomography artery (CTA) and postoperative ultrasound detected the presence of sciatic artery on both sides and thrombosis causing obstruction of left sciatic artery. Thrombectomy of the left iliac artery was performed.

Result: Three months follow up with clinical examination and ultrasound shows a good result. The patient had no intermittent claudication and could walk normally. Ultrasound presented a good circulation of the anterior and posterior tibial arteries.

Conclusion: PSA is a very rare condition. Diagnosis is based on CTA and ultrasound, but difficult in less experience with this disease. Treatment choice depends on the features of anatomical abnormalities. ${ }^{5}$

Keyword: sciatic artery, thrombosis, embolism.

\section{TỔNG QUAN}

Tồn tại ĐM ngồi là tổn thương bẩm sinh hiếm gặp, có thể xảy ra ở một bên hoặc cả hai bên. Triệu chứng lâm sàng của bệnh phụ thuộc những biến chứng như phình, hẹp hoặc tắc mạch do huyết khối. Đặc trưng về bất thường giải phẫu được tác giả Pillet - Gauffre phân thành 5 [1].Tuy nhiên phân loại có ý nghĩa cho kế hoạch điều thị thì được Ahn-Min phân thành 5 nhóm, dựa theo sự phát triển của động mạch đùi và tồn tại của ĐM ngồi [1]. Bệnh nhân thường được phát hiện tồn tại ĐM ngồi khi đi khám do các

\footnotetext{
*Bệnh viện quân y 103, học viện Quân y

Ngưòi chịu trách nhiệm khoa học: BS Nguyễn Thế Kiên

Ngày nhận bài: 31/12/2020 - Ngày Cho Phép Đăng: 26/01/2021
} 
bệnh lý khác hoặc biến chứng của động mạch này gây ra. Siêu âm, hay là các xét nghiệm có giá trị chẩn đoán. Thái độ điều trị phụ thuộc vào đặc điểm bất thường giải phẫu và triệu chứng lâm sang do thiếu máu của bệnh nhân. Chúng tôi xin chia sẻ kinh nghiệm chẩn đoán và điều trị một bệnh nhân tồn tại ĐM ngồi hai bên với hai khác nhau và có biến chứng huyết khối gây tắc mạch bên trái cấp tính.

\section{CA LÂM SÀNG}

Bệnh nhân nữ, 70 tuổi, không có tiền sử bệnh lý tim mạch hoặc chấn thương, vào viện do thiếu máu cấp tính chân trái ngày thứ 3 . Lâm sàng biểu hiện cẳng-bàn chân trái lạnh, đau, giảm vận động, không bắt được mạch bẹn, khoeo, mu chân, ống gót trái.

Chụp CTA chi dưới thấy huyết khối gây tắc từ động mạch chậu gốc bên trái trở xuống và tồn tại ĐM ngồi bên phải (hình 1). Siêu âm không thấy tín hiệu Doppler ở động mạch đùi, khoeo bên trái, trong lòng có huyết khối đồng âm.

Bệnh nhân được phẫu thuật lấy huyết khối động mạch chậu gốc, chậu ngoài, đùi nông, đùi sâu bên trái bằng Fogarty qua đường mở động mạch đùi. Trong quá trình phẫu thuật, không luồn được Fogarty $2 \mathrm{~F}$ qua động mạch khoeo trái. Sau phẫu
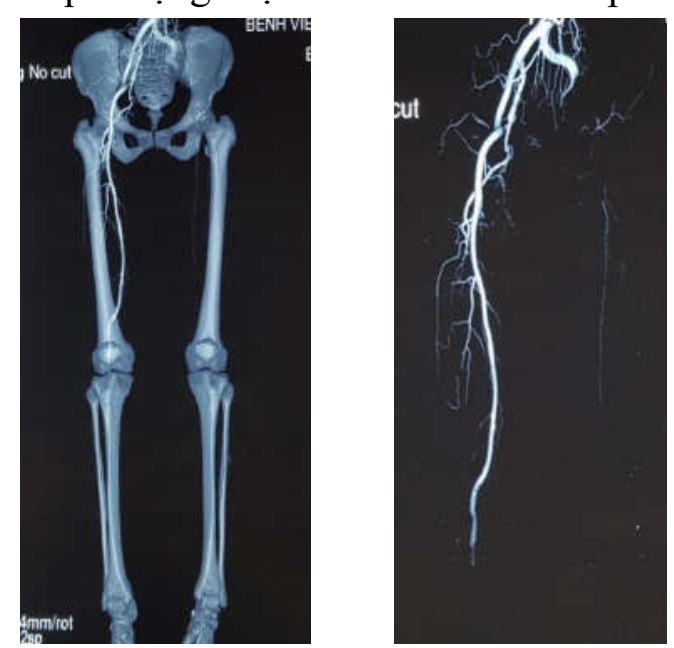

Hình 1. Tắc toàn bộ tù động mạch chậu gốc trái trở xuống do huyết khối. Tồn tại động mạch ngồi bên phải nhóm II (Ahn-Min). thuật, bệnh nhân đỡ đau cẳng-bàn chân trái, chân trái ấm, vận động bình thường. Mạch khoeo, mu chân, ống gót mờ hơn so với chân phải, $\mathrm{SpO} 2$ 96\%.

Sau phẫu thuật, kết quả chụp CTA chi dưới xác định có bất thường giải phẫu động mạch chi dưới bên trái. Động mạch đùi trái không nối trực tiếp với động mạch khoeo mà thông qua các nhánh tuần hoàn bên từ động mạch đùi sâu và đùi nông; động mạch đùi nông chia sớm, ngay dưới ngã ba động mạch đùi $3 \mathrm{~cm}$; đường kính động mạch đùi nông bên trái nhỏ hơn động mạch đùi nông phải; tắc động mạch chậu trong bên trái ngay chỗ phân chia động mạch chậu; hình ảnh cắt cụt thuốc động mạch khoeo phía trên các vòng nối (Hình 2). Siêu âm thấy tồn tại ĐM ngồi bên trái tùy hành với thần kinh hông to trái, kích thước lớn, nối với động mạch khoeo, trong lòng có huyết khối bán cấp tính, không còn tín hiệu dòng chảy trên Doppler.

Bệnh nhân ra viện, điều trị nội khoa. Theo dõi sau 3 tháng, bệnh nhân không có đau cách hồi, giảm rối loạn cảm giác, đi lại bình thường. Siêu âm kiểm tra thấy lưu thông máu từ động mạch khoeo xuống động mạch chày trước, chày sau tốt.
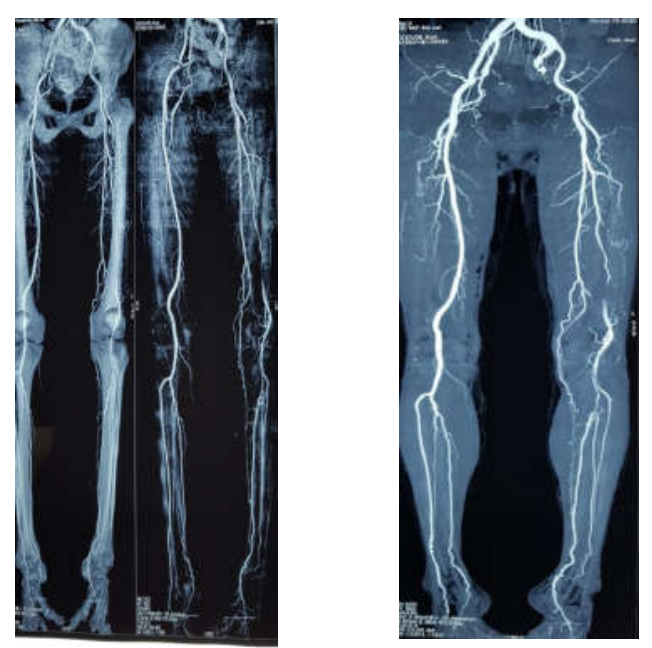

Hình 2. Động mạch đùi nông bên trái phát triển không hoàn toàn. Tồn tại ĐM ngồi bên trái nhóm III (Ahn-Min), nhung bị tắc do huyết khối. 


\section{BÀN LUẬN}

\section{Chẩn đoán}

Động mạch ngồi là một nhánh của ĐM chậu trong, bắt nguồn từ động mạch dây rốn trong thời kỳ bào thai, cung cấp máu cho sự phát triển của chi dưới. Khi động mạch đùi phát triển từ động mạch chậu ngoài, động mạch này dần sẽ teo nhỏ lại [2], [3]. Tồn tại ĐM ngồi xảy ra khi động mạch đùi không phát triển, xuất hiện với tỉ lệ rất nhỏ, khoảng $0,025 \%$ - 0,04\% [4]. Tuy tỉ lệ thấp nhưng biến chứng phình và/hoặc tắc mạch ở bệnh nhân này lại rất cao, với tỷ lệ lên tới 48\% [5].

Những trường hợp bắt được mạch khoeo, mu chân, ống gót nhưng không bắt được động mạch bẹn thì phải nghĩ tới tồn tại ĐM ngồi [3]. Chụp CTA là lựa chọn hàng đầu trong chẩn đoán bệnh này [5]. Tuy nhiên, bệnh nhân của chúng tôi vào viện vì huyết khối gây tắc hoàn toàn từ động mạch chậu gốc trở xuống, thuốc cản quang không vào được đoạn ngoại vi nên không thể xác định được bất thường giải phẫu ở bên trái trên CTA. Theo tác giả M. E. Aziz và cộng sự, nếu chưa từng gặp bệnh nào tương tự thì sẽ không nghĩ tới bệnh này [6]. Chúng tôi cũng chưa gặp trường hợp nào bất thường giải phẫu nào tương tự nên quá trình siêu âm cũng không tập chung khảo sát bất thường động mạch chậu trong. Trên CTA thấy tồn tại ĐM ngồi bên phải III (theo Pillet Gauffre). Cùng với đó, trong quá trình phẫu thuật, chúng tôi không thể đưa Fogarty $2 \mathrm{~F}$ xuống qua khoeo, đây là yếu tố gợi ý đến bất thường giải phẫu động mạch chân trái. Sau phẫu thuật, chụp CTA chi dưới cho thấy bất thường giải phẫu ở động mạch đùi trái thiểu sản và chia nhánh sớm hơn so với bên phải. Khảo sát siêu âm phát hiện thấy tồn tại ĐM ngồi, huyết khối toàn bộ lòng động mạch từ động mạch chậu trong đến đoạn nối với động mạch khoeo.

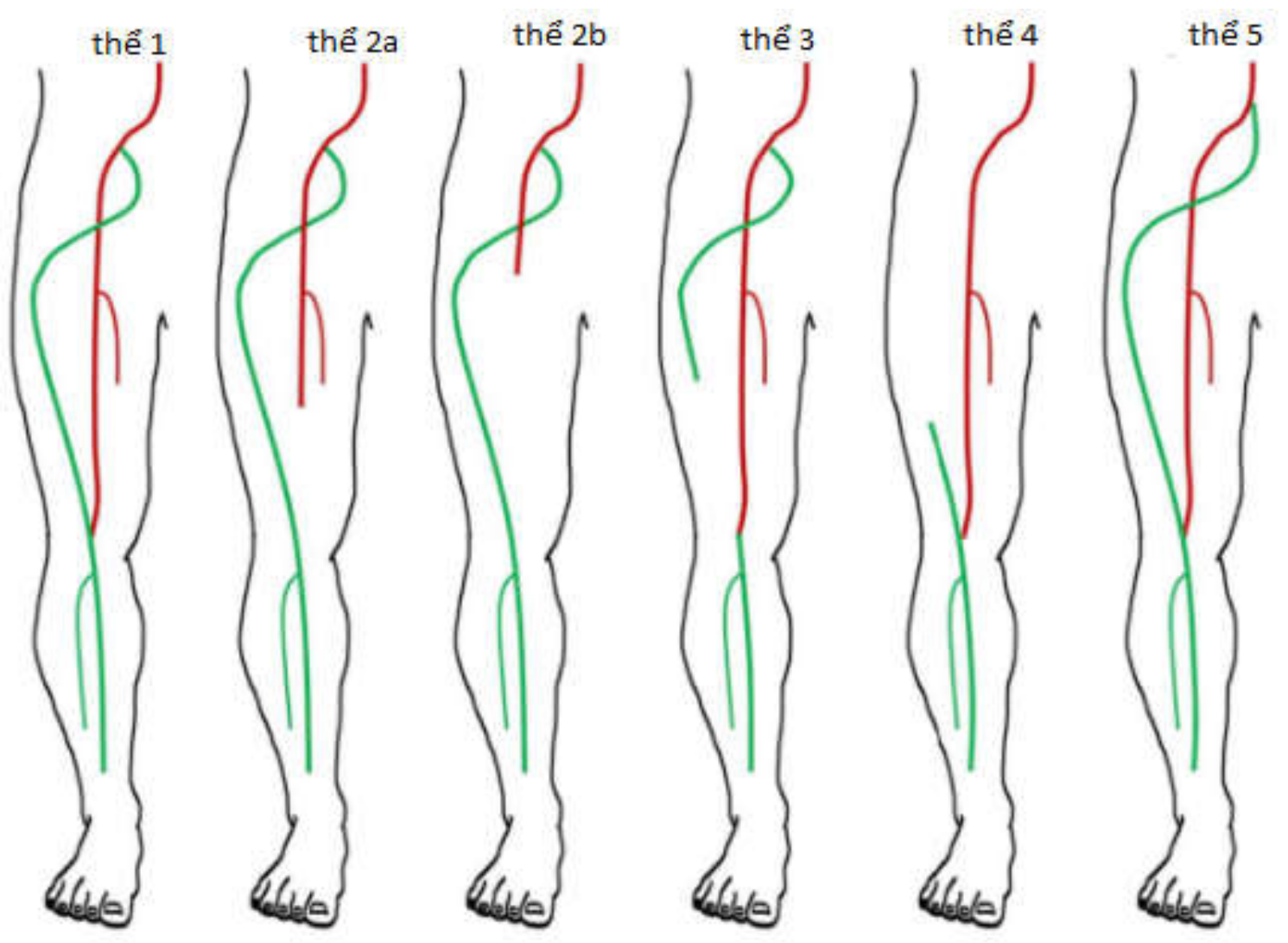

Hình 3: 

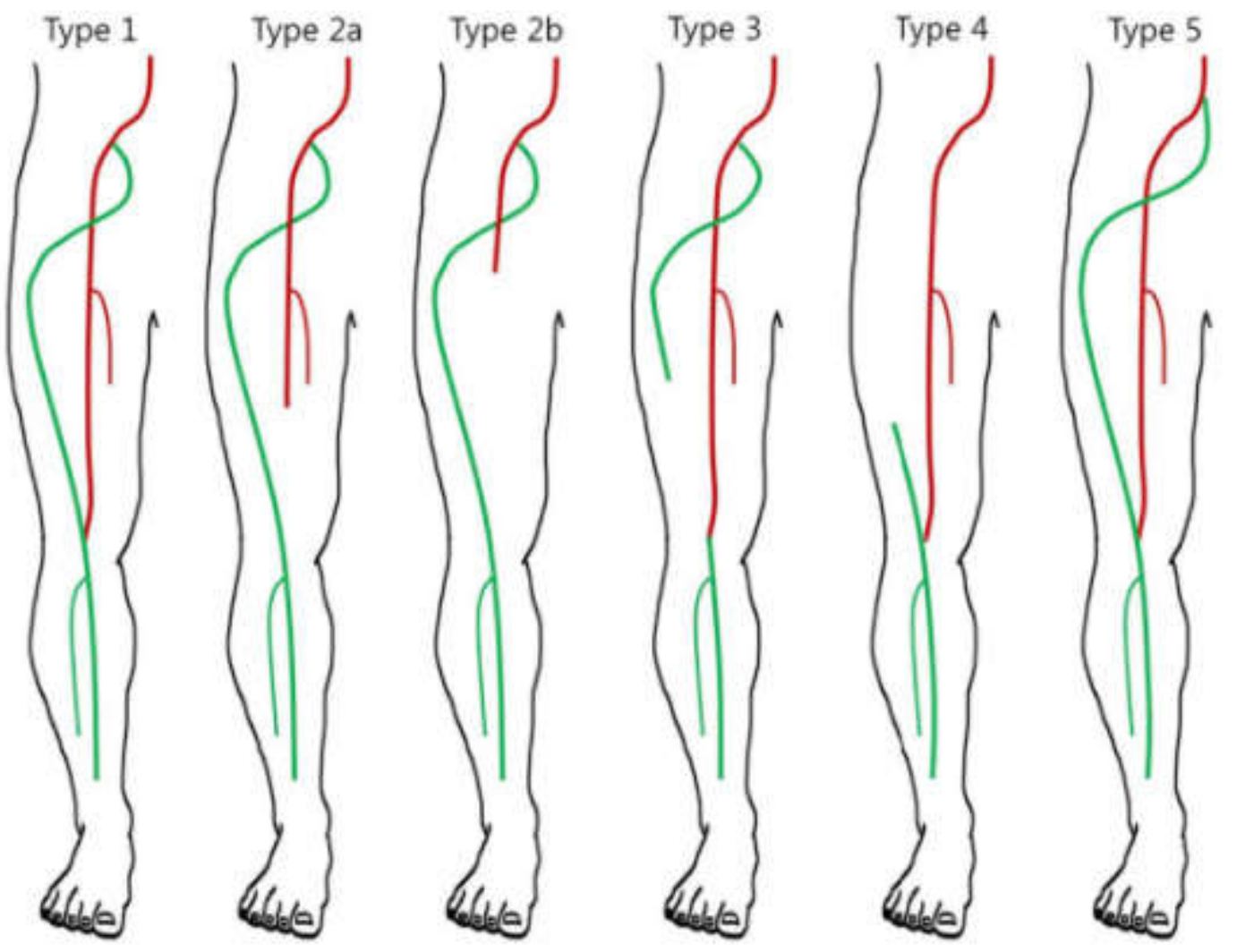

Điều trị

Lựa chọn biện pháp điều trị phải dựa vào đặc điểm lâm sàng và đặc điểm bất thường giải phẫu của ĐM ngồi [1], [4] trong đó đặc điểm lâm sàng giữ vai trò quan trọng. Phân loại theo Pillet Gauffre chỉ cho chúng ta biết về đặc điểm bất thường giải phẫu của hệ động mạch chi dưới. Phân loại mới theo Ahn-Min vừa cho biết về bất thường giải phẫu, đồng thời định hướng đến chiến lược điều trị cho bệnh nhân [1]. Bệnh nhân của chúng tôi ban đầu chưa xác định được có tồn tại ĐM ngồi bên trái, chỉ xác định được bệnh nhân có tắc mạch cấp do huyết khối nên có chỉ định phẫu thuật lấy huyết khối qua đường mở động mạch đùi. Kết quả chụp CTA chi dưới phát hiện bệnh nhân tồn tại ĐM ngồi bên trái thuộc nhóm III theo phân loại mới của Ahn-Min, và II theo phân loại của Pillet - Gauffre.

Những bệnh nhân nhóm III (theo Ahn Min), II (theo Pillet - Gauffre) có triệu chứng lâm sàng tắc mạch và biến chứng phình mạch thì

có chỉ định can thiệp trên túi phình và/hoặc tái tưới máu để dự phòng huyết khối và thiếu máu ngoại vi [1], [4]. Tuy nhiên, trên bệnh nhân này, sau phẫu thuật lấy huyết khối thấy tưới máu chi dưới tốt, chi ấm, vận động bình thường, rối loạn cảm giác cải thiện rõ rệt. Đồng thời trên MSCT thấy tuần hoàn bên từ động mạch đùi nông, sâu xuống động mạch khoeo rất tốt, chỉ số $\mathrm{ABI} 0,75$. Những bệnh nhân chỉ có triệu chứng đau cách hồi vừa phải, không có biến chứng phình mạch thì không cần thiết phải can thiệp mạch hay phẫu thuật, và nên theo dõi bằng siêu âm mạch máu [2], [7]. Bệnh nhân của chúng tôi sau phẫu thuật lâyy huyết khối, điều trị nội khoa 3 tháng có kết quả tốt, cẳng - bàn chân ấm, hết đau cách hồi, mạch mu chân, ống gót bắt rõ. Vì vậy chúng tôi quyết định không phẫu thuật hay can thiệp gì thêm trên bệnh nhân này.

\section{KẾT LUẬ̣}

Tồn tại ĐM ngồi là tình trạng rất hiếm gặp. 
Chẩn đoán dựa vào CTA, siêu âm mạch máu nhưng sẽ khó khăn nếu chưa có kinh nghiệm về bệnh. Điều trị phụ thuộc vào đặc điểm lâm sàng do thiếu máu, phình mạch và bất thường giải phẫu.

\section{TÀI LIẸU THAM KHẢO}

1. Ahn, S., et al., Treatment Strategy for Persistent Sciatic Artery and Novel Classification Reflecting Anatomic Status. Eur J Vasc Endovasc Surg, 2016. 52(3): p. 360-9.

2. Mandell, V.S., et al., Persistent sciatic artery: clinical, embryologic, and angiographic features. AJR Am J Roentgenol, 1985. 144(2): p. 245-9.

3. Santaolalla, V., et al., Persistent sciatic artery. Ann Vasc Surg, 2010. 24(5): p. 691 e7-10.
4. Choi, Y.K., et al., Treatment of complete persistent sciatic artery with distal thromboembolism by thromboembolectomy only. Korean J Thorac Cardiovasc Surg, 2012. 45(5): p. 342-4.

5. van Hooft, I.M., et al., The persistent sciatic artery. Eur J Vasc Endovasc Surg, 2009. 37(5): p. 585-91.

6. Aziz, M.E., et al., Bilateral persistent sciatic arteries with unilateral complicating aneurysm. Singapore Med J, 2005. 46(8): p. $426-8$.

7. Brantley, S.K., E.E. Rigdon, and S. Raju, Persistent sciatic artery: embryology, pathology, and treatment. J Vasc Surg, 1993. 18(2): p. 242-8. 